\title{
PEMANFAATAN TUMBUHAN SEBAGAI BAHAN PANGAN OLEH MASYARAKAT DISEKITAR HUTAN DESA LINGKAR INDAH KECAMATAN SAYAN KABUPATEN MELAWI
}

(Utilization of Plants as Food Materials by the Community Around the Forest of Lingkar Indah, Village Sayan District, Melawi Regency)

\author{
Adwi Sri Rahmi, Gusti Eva Tavita, Nurhaida
}

Fakultas Kehutanan Universitas Tanjungpura Pontianak, Jl.Daya Nasional Pontianak 78123 Email: adwisrirahmi17@gmail.com

\begin{abstract}
The purpose of the study was to obtain data on the types of plants used as food by the community around the forest of Lingkar Indah Village Sayan District Melawi Regency. The study was carried out in Lingkar Indah Village 4 weeks effective in the field. The used is survey and observation with direct interview techniques. The technique by using purposive sampling. There were 104 plants recorded as food that were used by the community, with 48 identified families. Utilization of plants as food material is mostly from tree habitus (49 species), the type of food material that is mostly obtained is fruits (58 species), the most widely used part is fruit (75 species). The most widely used processing is directly consumed, and the highest Use Value (UV) value is bay leaf (Syzygium polyanthum Wight) 0,7 and the highest Famili Importance Value (FIV) Anacardiaceae with a value of $36,84 \%$.
\end{abstract}

Keywords: Foodstuffs, Lingkar Indah Village Plants, Utilization

\section{PENDAHULUAN}

Tumbuhan bahan pangan yaitu spesies tumbuhan yang diketahui atau dipercaya masyarakat memiliki fungsi yang biasa menggantikan sumber makanan yang mana dapat diolah secara tradisional dan didapat dengan mudah di dalam hutan. Pengembangan jenisjenis tanaman pangan liar hanya terbatas dilakukan oleh masyarakat hutan pedalaman atau masyarakat adat yang memanfaatkannya pada lingkup sangat kecil secara lokal untuk kebutuhan sendiri Hidayat, (2010). Penelitian pemanfaatan tumbuhan di Kalimantan Barat khususnya tumbuhan yang berguna sebagai bahan pangan telah banyak di teliti oleh beberapa peneliti, seperti penelitian Irsyad et al. (2013) ditemukan 90 jenis tumbuhan sebagai bahan pangan, bahan pangan dibedakan sebagai bahan pangan pokok yaitu padi (O. sativa) dan bahan pangan tambahan yaitu terong (S. melongena), singkong ( $M$. utillissima), dan sereh ( $C$. nardus). Jenis tumbuhan yang sering dijadikan sebagai bahan pangan oleh manusia berupa tumbuhan yang memiliki kandungan karbohidrat melimpah dan jenis tumbuhan lain yang dapat menghasilkan energi. Bagianbagian tumbuhan yang dapat dimanfaatkan pun beragam, mulai dari akar, batang, daun, bunga, biji, hingga buahnya, tumbuhan pun dapat dimanfaatkan manusia dalam berbagai aspek kehidupan Sisilahi et al.(2018).

Masyarakat di Desa Lingkar Indah Kecamatan Sayan masih memanfaatkan tumbuhan pangan karena masih memiliki kawasan hutan yang cukup luas, sehingga terdapat berbagai jenis 
tumbuhan pangan yang tumbuh di sekitar hutan. Tumbuhan pangan tersebut dimanfaatkan oleh masyarakat karena sulit untuk memperoleh bahan pangan seperti sayuran.Oleh sebab itu penelitian perlu dilakukan agar didapatkan data tentang bagaimana pola pemanfaatan tumbuhan pangan agar menjadi bahan konsumsi alternatif yang baik.Tujuan penelitian ini untuk mendapatkan data mengenai pemanfaatan jenis tumbuhan yang dimanfaatkan sebagai bahan pangan beserta cara pengolahan oleh masyarakat disekitar hutan Desa Lingkar Indah. Selain itu juga untuk mendapatkan jumlah penggunaan Use Value (UV) serta nilai guna famili tumbuhan Famili Importance Value (FIV).

Manfaat penelitian ini adalah diharapkan dapat menambah pengetahuan dan sebagai sarana masyarakat dalam upaya melestarikan jenis tumbuhan pangan yang ada di Desa Lingkar Indah Kecamatan Sayan Kabupaten Melawi.

\section{METODOLOGI}

Penelitian dilaksanakan di Desa Lingkar Indah Kecamatan Sayan Kabupaten Melawi, Penelitian mulai dari 4 Maret sampai 18 Maret 2019. Alat yang digunakan peta lokasi, kamera, kuisioner, alat perekam suara, alat tulis, buku identifikasi.

\section{Prosedur Penelitian}

Metode yang digunakan dalam penelitian ini adalah metode survey dan observasi dengan teknik wawancara langsung. Pengumpulan data menggunakan alat bantu yaitu daftar pertanyaan atau kuisioner berupa bentuk-bentuk pertanyaan yang diarahkan kepada sejumlah responden. Pengambilan sampel di lokasi penelitian dilakukan dengan menggunakan purposive sampling. Responden dipilih dengan mengutamakan kepala keluarga, dan pemilihan jumlah responden dipilih menggunakan rumus slovin berikut (Sarwono, 2006):

$\mathrm{n}=\frac{N}{N(d)^{2}+1}$

Keterangan:

$\mathrm{n}=$ Sampel

$\mathrm{N}=$ Populasi

$\mathrm{d}=$ Derajat kebebasan $(0,05)$

Berdasarkan perhitungan dengan menggunakan rumus slovin diperoleh jumlah responden sebanyak $42 \mathrm{KK}$ dari $264 \mathrm{KK}$ yang ada.

Metode pengumpulan data dilakukan dengan teknik wawancara langsung terhadap masyarakat sebagai responden dengan bantuan kuisioner.

Data yang dikumpulkan dalam penelitian ini meliputi data sekunder dan data primer. Data sekunder merupakan data yang diperoleh secara tidak langsung, data dapat diperoleh dari Badan Pusat Statistik Desa/Kecamatan/Kabupaten, studi literatur, aksebilitas dan lainya. Data primer merupakan data yang diperoleh secara langsung melalui wawancara terhadap responden terpilih dan pengamatan langsung tumbuhan bahan pangan yang meliputi: Nama Lokal, Nama Indonesia, Nama Latin, Habitus, Jenis bahan pangan ( buah-buahan, sayur-sayuran, sumber karbohidrat, 
sereal, bumbu, dan minuman).Bagianbagian tumbuhan yang digunakan sebagai bahan pangan (buah, bunga, daun, batang, kulit, akar, dan lain-lain).

\section{HASIL DAN PEMBAHASAN}

Berdasarkan hasil penelitian dilapangan, diperoleh 76 orang responden terpilih, terdiri atas laki-laki sebanyak 35 orang dan perempuan sebanyak 41 orang, responden terpilih dari dua dusun yaitu Dusun Mempahung dan Tanjung jati. 76 orang responden terpilih diperoleh dari 42 jumlah kepala keluarga (KK), bila dipersentasekan menjadi $16 \%$ dimana jumlah total kepala keluarga $(\mathrm{KK})$ di Desa Lingkar Indah sebanyak 264.

\section{PemanfaatanTumbuhanPangan}

Hasil penelitian memperoleh 104 spesies tumbuhan yang termasuk kedalam 48 famili, yang dimanfaatkan olehmasyarakat Desa Lingkar Indah Kecamatan Sayan Kabupaten Melawi sebagai bahan pangan. Data tumbuhan pangan yang meliputi nama lokal, nama Indonesia, nama latin, habitus, jenis bahan pangan, bagian digunakan, cara pengolahan, dan Use Value (UV), serta Famili Importance Value (FIV). Perhitungan dilakukan sebagai berikut:

a. Menggunakan rumus (Kayani et al. 2015):

$\mathrm{UVs}=\frac{\sum \mathrm{U}}{\mathrm{n}}$

Keterangan:

UV : Nilai Use Value

$\sum \mathrm{U}$ : Jumlah laporan penggunaan yang dikutip oleh masing-masing responden untuk spesies yang diberikan.

$\mathrm{n}$ : Jumlah total responden.

\section{b. Famili Importance Value (FIV)}

untuk mengetahui famili tumbuhan

yang paling banyak digunakan, dihitung menggunakan rumus

Napagoda et al. (2015):

$\mathrm{FIV}=\frac{F C(\text { Famili })}{N} \times 100$

Keterangan:

FIV : Famili Use Value

FC : Jumlah responden yang

menyebutkan keluarga

$\mathrm{N}$ : Jumlah total responden

Hasil Pengamatan Tumbuhan

Sebagai Bahan Pangan

Habitus

Habitus atau ciri-ciri umum tumbuhan sebagai bahan pangan yang ditemukan dalam penelitian ini sangat bervariasi, mulai dari tumbuhan habitus pohon 49 jenis, contohnya Asam gandis (G.xanthochymus Hook) dan Pulasan (N.mutabileLinnaeus). Habitus palma 4 jenis, contohnya Kelapa ( $C$. nuciferaLinnaeus) dan Aren (A. pinnata). Habitus perdu 13 jenis,contohnya Cabe (C. annuum Bird's Eye) dan Terong ungu ( $S$. melongenaLinnaeus). Habitus Rumputrumputan 5 jenis, contohnya $\operatorname{Padi}(O$. Sativa Linnaeus) dan Bambu (Bambusa $s p$ ). Habitus semak 3 jenis, contohnya Cengkodok (M. Malabathrichum Linnaeus). Habitus herba 16 jenis, contohnya Genjer (L. flava). Habitus liana 12 jenis, contohnya Pare $(M$. charantiaLinnaeus). Habitus pakupakuan 2 jenis, contohnya Pakis ( $S$. palustris). Adapun tumbuhan bahan pangan berdasarkan habitus dapat dilihat pada Gambar 3. 
JURNAL HUTAN LESTARI (2020)

Vol. 8 (4): 840 - 847

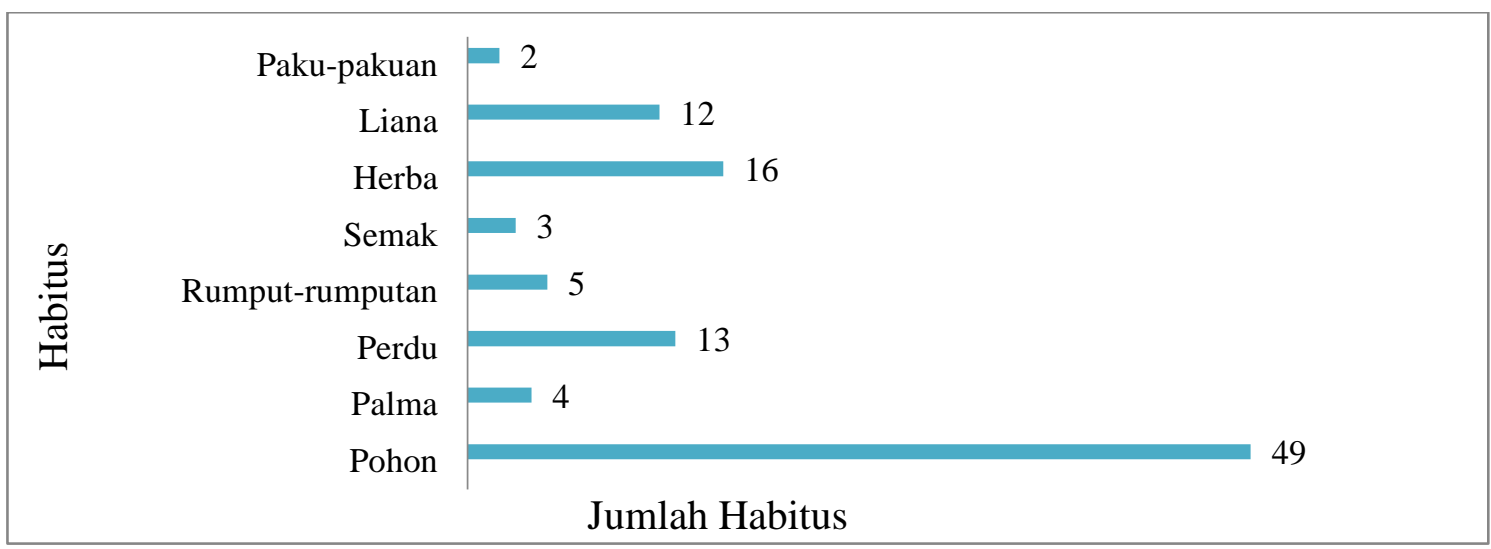

Gambar 3. Tumbuhan Bahan Pangan Berdasarkan Habitus (Food plants based on habitus)

Habitus tumbuhan bahan pangan yang paling banyak ditemukan yaitu pohon, hal ini dikarenakan jenis-jenis tumbuhan dan habitus pohon yang sering dijumpai dan banyak terdapat di sekitar lingkungan masyarakat. Selain itu habitus pohon mempunyai nilai yang paling tinggi karena daya tahan hidup pohon lebih lama dibandingkan dengan habitus yang lainnya. Hasil persentase habitus penelitian ini lebih banyak dari hasil persentase habitus dipenelitian (Dasman, 2015) dengan jumlah habitus pohon 47, yang dilaksanakan di Desa Nanga Kompi Kecamatan Sayan Kabupaten Melawi.

\section{Jenis Bahan Pangan}

Terdapat berbagai jenis bahan pangan yang ditemukan dalam penelitian ini, mulai dari Buah-buahan 58 jenis, contohnya Mangga (M.indica) dan Nangka (A.heterophyllus Lam). Sayursayuran 31 jenis, contohnya Kangkung ( $I$. aquatic Forsk) dan Genjer (L.flava). Minuman 3 jenis, contonya Tebu (S.officinarum Linnaeus) dan Kelapa (C.nucifera Linnaeus). Bumbu 7 jenis, contohnya Kencur ( $K$. galangal Linnaeus) dan Kunyit (C. longa Linnaeus). Sereal 3 jenis, contohnya Kacang panjang (V.unguiculata Linnaeus) dan Kacang tanah (A.hypogaea Linnaeus). Karbohidrat 2 jenis, yaitu Ubi jalar (I. batatas Linnaeus) dan Padi (O. sativa Linnaeus).

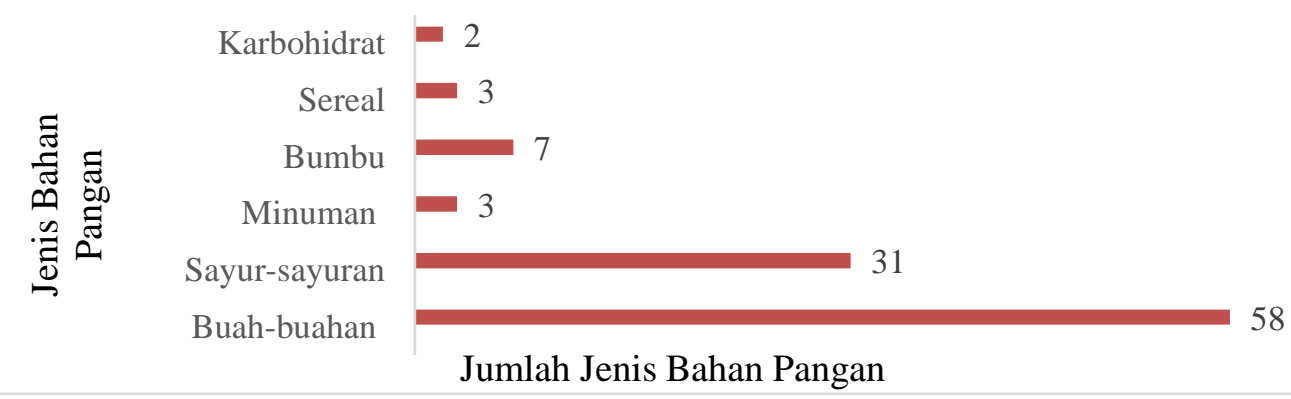

Gambar 4. Jenis Bahan Pangan yang Ditemukan Dilapangan (Types of food found in the field) 
Jenis bahan pangan yang paling banyak ditemukan dalam penelitian ini adalah jenis buah-buahan. Karena jenis buah-buahan sangat mudah dan sering dijumpai oleh masyarakat di sekitar hutan dan biasa dibudidayakan untuk diperdagangkan. Jumlah persentase jenis bahan pangan yang diperoleh sebanding dengan penelitian (Dasman, 2015) dengan jumlah jenis bahan pangan buah-buahan 52 jenis ,yang dilaksanakan di Desa Nanga Kompi Kecamatan Sayan Kabupaten Melawi.

\section{Bagian yang Digunakan}

Dalam penelitian ini banyak bagian-bagian tumbuhan bahan pangan yang digunakan, mulai dari Buah 75 jenis, contohnya Durian (D. zibethinus, Linnaeus). Bunga1 jenis, yaitu Kecombrang (E.elatior). Daun 12 jenis, contohnya Cangkok manis ( $S$. androgynous). Batang 2 jenis, yaitu Serai (C.citratus DC) dan Tebu (S.officinarum Linnaeus). Biji4 jenis, contohnya Petai (P.speciosa Lamk). Umbut 2 jenis, yaitu Rotan (C.rotang Miq) dan Bambu (Bambusa Sp). Umbi 6 jenis, contohnya Talas (C. Esculenta Linnaeus). Daun dan umbi 1 jenis, yaitu Kucai (A.tuberosum Rottler dan A.ramosus). Daun dan buah 1 jenis, yaitu Melinjo (G.gnemon Linnaeus).

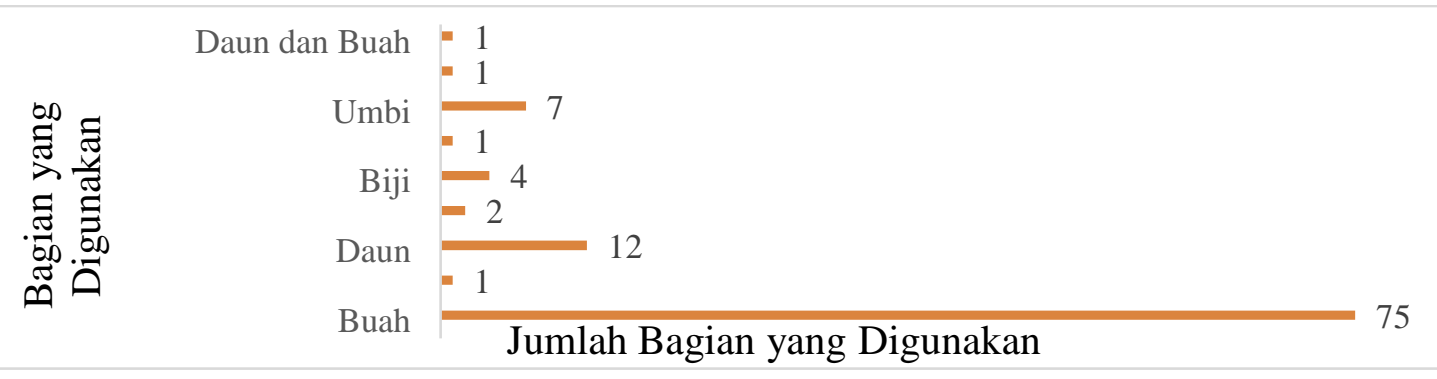

Gambar 5. Bagian Bahan Pangan yang Digunakan (The part of food used)

Bagian tumbuhan bahan pangan yang digunakan antara lain buah, bunga, daun, batang, biji, umbut, umbi, daun dan umbi, serta daun dan buah. Bagian yang paling banyak digunakan oleh masyarakat yaitu bagian buah dengan jumlah 75 jenis. Karena bagian buah paling banyak ditemui dan mudah didapat oleh masyarakat. Persentase bagian yang digunakan pada penelitian ini lebih banyak jumlahnya dibandingkan dengan penelitian (Camelia et al. 2019) dimana bagian yang digunakan hanya sebanyak 55 jenis di Kecamatan Simpang Teritip Kabupaten Bangka Barat.

\section{Cara Pengolahan}

Dalam penelitian ini ada beberapa jenis cara pengolahan tumbuhan bahan pangan, yaitu mulai dari disambal 10 jenis, contohnya Tomat (S.melongena Linnaeus). Ditumis 9 jenis, contohnya daun singkong (M.utilissima Pohl). Ditumbuk 6 jenis, contohnya Lengkuas (A.galangal Linnaeus). Digoreng 2 jenis, yaitu Djuping (P.motley Hook) dan Sukun (A.altilis Park). Direbus 16 jenis, contohnya Kemayau (D.rostrata Blume). diperas 2 jenis, yaitu Jeruk sambal (C.amblycarpa Hassk) dan Tebu (S.officinarum Linnaeus). Sedangkan cara pengolahan dengan dikukus 1 jenis, 
yaitu Padi (O.sativa Linnaeus).

Dikonsumsi langsung 46 jenis, contohnya Manggis (G.mangostana Linnaeus). dikeringkan/dijemur 3 jenis, contohnya Asam kandis $(G$. xanthochymus Hook). direbus/disambal 3 jenis, contohnya Terong pipit
(S.torvum $\mathrm{Sw}$ ). ditumis/direbus 4 jenis, contohnya Mentimun (C. sativus Linnaeus). ditumbuk/diiris 1 jenis, yaitu Cabe ( $C$. annuum Bird's Eye), dan disambal/ditumis 1 jenis, yaitu Pare belut (T.cucumerina Linnaeus).

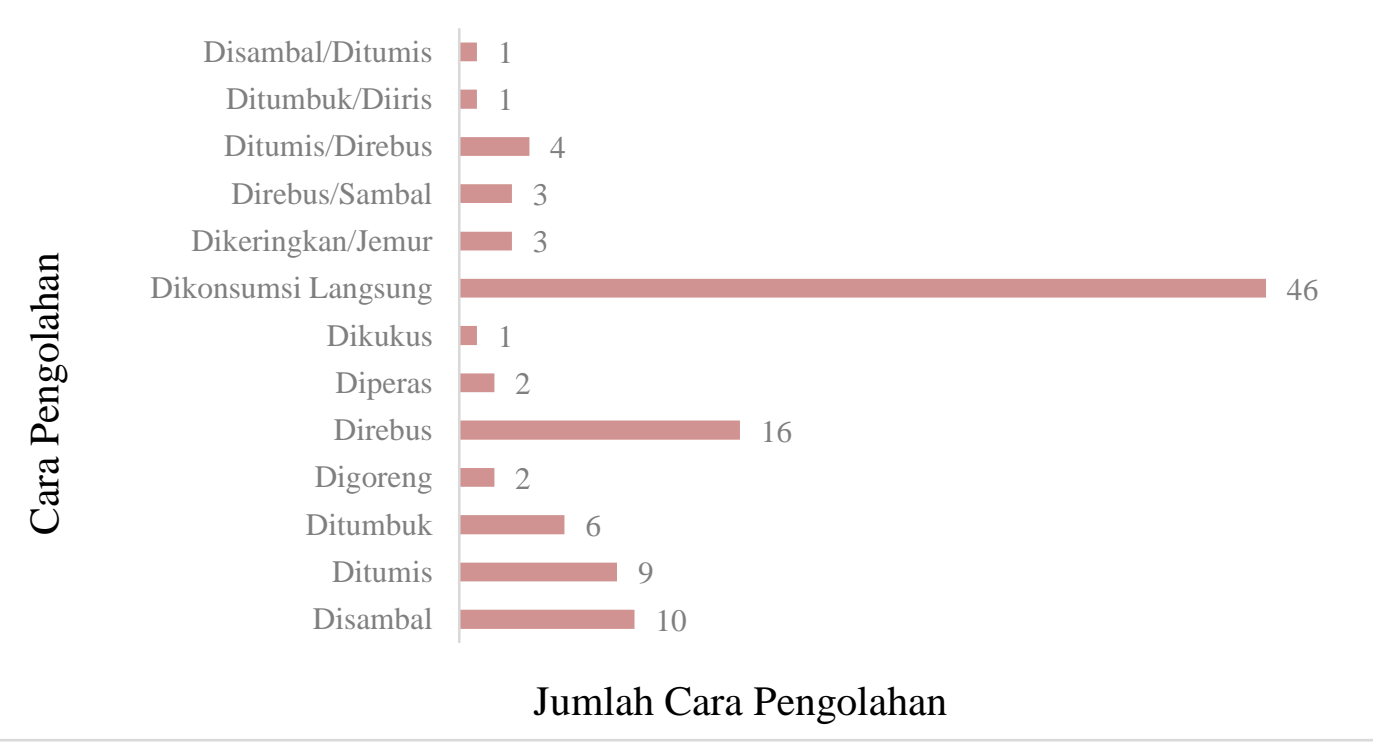

Gambar 6. Cara Pengolahan Tumbuhan Bahan Pangan (How to process food plants)

Cara pengolahan tumbuhan bahan pangan yang dilakukan oleh masyarakat seperti disambal, ditumis, ditumbuk, digoreng, direbus, diperas, dikukus, dikonsumsi langsung, dikeringkan/dijemur, direbus/disambal, ditumis/direbus, ditumbuk/diiris, disambal/ditumis.

Berdasarkan hasil penelitian cara pengolahan yang paling banyak digunakan adalah dengan cara dikonsumsi langsung, dengan jumlah 46 jenis tumbuhan yang mudah ditemukan dilingkungan masyarakat. Jumlah persentase cara pengolahan tumbuhan pangan ini sebanding dengan penelitian (Dasman, 2015) 41 jenis tumbuhan dengan cara dikonsumsi langsung di Desa Nanga
Kompi Kecamatan Sayan Kabupaten Melawi.

\section{Kesimpulan}

Berdasarkan hasil penelitian terhadap jenis tumbuhan bahan pangan dan pemanfaatannya di Desa Lingkar Indah Kecamatan Sayan Kabupaten Melawi dapat disimpulkan yaitu :

1. Tumbuhan pangan yang dimanfaatkan oleh masyarakat Desa Lingkar Indah diperoleh 104 spesies tumbuhan pangan teridentifikasi yang termasuk kedalam 48 famili dan 8 habitus. Family yang paling banyak dimanfatkan adalah Anacardiaceae dan Fabaceae yaitu 7 spesies. Habitus yang paling banyak ditemukan yaitu habitus pohon sebanyak 49 spesies. 
2. Buah-buahan merupakan jenis bahan pangan yang paling banyak dimanfaatkan yaitu 58 spesies, sedangkan jenis bahan pangan yang paling sedikit dimanfaatkan adalah karbohidrat yaitu 2 spesies. Bagian tumbuhan yang paling banyak digunakan adalah buah, sebanyak 75 spesies, yang paling sedikit digunakan yaitu bunga dan umbut yaitu masingmasing 1 spesies. Cara pengolahan tumbuhan pangan yang paling banyak dilakukan oleh masyarakat adalah dikonsumsi langsung 46 spesies, sedangkan yang paling sedikit yaitu dikukus 1 spesies. Use Value (UV) tertinggi adalah daun salam (Syzygium polyanthum) dengan nilai $(0,7)$ dan Famili Importance Value (FIV) tertinggi Anacardiaceae dengan nilai $(36,84 \%)$.

\section{Saran}

1. Mengingat tumbuhan bahan pangan merupakan salah satu aset penting bagi kelangsungan hidup masyarakat seharihari, maka tumbuhan bahan pangan perlu dikembangkan dan dibudidayakan sehingga bisa meringankan kebutuhan pangan serta diperdagangkan.

2. Perlu adanya penelitian lebih lanjut ke hutan Desa Lingkar Indah, karena banyak tumbuhan bahan pangan yang masih belum tahu nama ilmiah atau nama Indonesianya.

\section{DAFTAR PUSTAKA}

Arieska C, Budi A, Lina J. 2019. Studi Etnobotani Tanaman Pangan Suku Jerieng Di Kecamatan Simpang Teritip Kabupaten Bangka Darat.
Jurnal Penelitian Biologi, Botani, Zoologi dan Mikrobiologi. Vol 4 (1).

Donni S. 2015. Identifikasi Tumbuhan Sumber Pangan Di Hutan Tembawang Desa Aur Sampuk Kecamatan Sengah Temila Kabupaten Landak. Jurnal Hutan Lestari. Vol 4 (1) : 32-39.

Hidayat AAA. 2010. Metode Penelitian Kesehatan Paradigma Kuantitatif. Jakarta: Health Books.

Irsyad MN, Jumari, Murningsih. 2013. Studi Etnobotani Masyarakat Desa Sukolilo Kawasan Pegunungan Kendeng Pati Jawa Tengah. Bioma. 15 (1): 27-34.

Kayani S, Mushtaq A, Shazia S, Zabta KS, Muhammed Z, Ghulam Y, Manzoor H, dan Tahira B. 2015. Ethnobotany of Medicinal Plants Among the Communities of Alpine and Subalpine Regions of Pakistan. Journal of Ethnopharmacology. 164:186202.

Napagoda MT, Thamudi S, dan Diroshi F. 2018. An Ethnobotanical Study of the Medicinal Plants Used as AntiInflammatory Remedies in Gampaha District, Western Province, Sri Langka. Journal Scientifica. Vol 2018, Article ID 9395052:1-8.

Nurhidayah, Y. Lovadi, I. Linda, R. 2015. 'Tumbuhan Berpotensi Bahan Pangan Di Desa Sebangun Kecamatan Sebawi Kabupaten Sambas', Jurnal Protobiont, vol.4, no.1, hal. 151-159.

Satrima, R. 2015. Kajian Etnobotani Tumbuhan Pangan Pada Masyarakat Suku Melayu Di Desa Boyan Tanjung Kabupaten Kapuas Hulu. Jurnal Protobiont. 4 (2) : 90-95. 
JURNAL HUTAN LESTARI (2020)

Vol. 8 (4): 840 - 847

Sastrapradja dan Widjaja, 2010, Keanekaragaman Sayuran dan Buah-buahan di Indonesia. Jakarta: Bumi Aksara.

Sisilahi M, Nisyawati, Anggraeni R. 2018. Studi Etnobotani Tumbuhan Pangan yang Tidak Dibudidayakan Oleh Masyarakat Lokal Sub-Etnis Batak Toba di Desa Peadungdung Sumatera Utara Indonesia. Jurnal Pengelolaan Sumberdaya Alam dan Lingkungan. Vol. 8 No. 2: 241-250.
Soedjono, 2008. Seri Industri Pertanian Kacang-Kacangan. CV Rusda. Bandung.

Yusuf D. 2015. Tumbuhan Sumber Pangan yang Dimanfaatkan oleh Masyarakat Sekitar Hutan Tembawang Desa Nanga Kompi Kecamatan Sayan Kabupaten Melawi. Jurnal Hutan Lestari. Vol 3 (2):332-336. 